
\title{
25 Research Square \\ Traditional Chinese Medicine Might Reduce Risk of Dementia in Patients with Parkinson's disease: A Population-based Nested Case-control Study
}

\section{Yun-Tzu Liang}

Chung Shan Medical University Hospital https://orcid.org/0000-0002-5950-0064

Chia-Yang Lin

Chung Shan Medical University Hospital

\section{Yu-Hsun Wang}

Chung Shan Medical University Hospital

\section{Hsi-Hsien Chou}

Chung Shan Medical University Hospital

James Cheng-Chung Wei ( $\nabla$ jccwei@gmail.com )

https://orcid.org/0000-0002-1235-0679

\section{Research}

Keywords: Dementia, Parkinson's disease, Traditional Chinese Medicine

Posted Date: May 22nd, 2020

DOl: https://doi.org/10.21203/rs.3.rs-29048/v1

License: (c) (i) This work is licensed under a Creative Commons Attribution 4.0 International License. Read Full License 


\section{Abstract}

Background Patients who have Parkinson's disease (PD) comorbid with dementia is common. With the prolonged life expectancy, dementia is gradually becoming prevalent and affects most patients' life qualities. However, the efficacy of current treatments in dementia of Parkinson's disease is limited. Previous studies indicated the potential roles of Traditional Chinese Medicine (TCM) in treating dementia, yet its effects in preventing dementia from Parkinson's patients are unknown.

Methods This case-control study was nested within a national health insurance database of patients over 50 years old with newly diagnosed Parkinson's disease from year 2000 to 2010 . Among these PD patients, dementia and non-dementia groups were discussed respectively in terms of the duration of taking TCM ( $\geq 90$ days versus $<90$ days), age (50-64 versus $\geq 65)$ and gender.

Results The risk of dementia in patients with Parkinson's disease is decreased by using TCM for < 90 days and $\geq 90$ days, especially in the group who took TCM for more than 90 days. The use of TCM significantly reduces the risk of dementia in the subgroups of age $\geq 65$ years, female patients using TCM for both $<90$ days and $\geq 90$ days, and male patients using TCM for $<90$ days. Overall, we can see the protection tendency among all of the target population under TCM use.

Conclusions The results showed that there is a significant reduction of nearly $38 \%$ in the risk of dementia for patients with Parkinson's disease after the usage of Traditional Chinese Medicine. The beneficial effects for using $T C M \geq 90$ days in women age $\geq 65$ years are most prominent.

Trial registration The study data were acquired from the Taiwan's National Health Insurance (NHI) Research Database. The NHI-claimed data provide clinical information for population-based epidemiologic research. This study was approved by the Institutional Review Board of Chung Shan Medical University Hospital.

\section{Background}

Parkinson's disease (PD) and other causes of dementia can occur at the same time. In addition, PD can lead to dementia itself.[1-2] According to the previous studies, the cumulative prevalence of dementia was $75-90 \%$ in PD, particularly in patients with PD for more than 10 years. [3] The incidence of dementia in $\mathrm{PD}$ patients is around $10 \%$ per year.[4] In the long-term, with the progression of the PD, dementia can affect up to $90 \%$ of patients with Parkinson's disease. Besides, there is a tendency that women with PD live longer than men with PD, and therefore higher chance of PD women to obtain dementia.[5] Studies suggested that with increasing life expectancy, dementia is almost inevitable in patients with PD, especially in women. Furthermore, current treatments in treating dementia of PD only provide limited effects and new treatments are slow in development.[6]

A previous study indicated that some Traditional Chinese Medicine (TCM) have specific effects on certain determining factors of dementia, such as acetylcholinesterase (AChE) inhibitors and neuronal injury 
inhibitors. Moreover, functions such as nootropic, anti-inflammation, anti-hypertension, antihyperlipidemia, anti-diabetes, anti-convulsion and curing cognition disorders are also noted in TCM. It is also stated in the analysis that the anti-dementia TCM formulae were directly associated with ameliorating dementia or having synergy and adjunctive effects.[7]

However, the effects of TCM in preventing dementia for patients who have Parkinson's disease were unknown. This study aims to accomplish this goal through a case-control study nested within a longitudinal health insurance database of patients.

\section{Methods}

\section{Data source}

The study data were obtained from the Taiwan's National Health Insurance Research Database. The National Health Insurance (NHI) is a compulsory program with coverage rate of $99.9 \%$ of the 23 million residents in Taiwan. The NHI-claimed data provide clinical information for population-based epidemiologic research. All diagnoses were coded using the International Classification of Diseases, Ninth Revision, Clinical Modification (ICD-9-CM) format. This study was approved by the Institutional Review Board of Chung Shan Medical University Hospital.

\section{Study subjects}

The study design is a nested case-control study. Eligible subjects fulfilled following conditions: $(1) \geq$ 50 years old $(2)$ newly diagnosed Parkinson's disease (ICD-9-CM $=332$ ) at least twice in outpatient department or one admission from year 2000 to 2010. (3) No known diagnosis of dementia (ICD-9-CM = 290.0-290.4, 294.1, 331.0-331.2) before diagnosis of Parkinson's disease.

\section{Exposure to traditional Chinese medicine and covariates}

The use of TCM was defined within three years before the index date and the prescription days were calculated to perform the cumulative usage effect. Baseline comorbidities included hypertension (ICD-9$C M=401-405$ ), hyperlipidemia (ICD-9-CM = 272.0-272.4), chronic liver disease (ICD-9-CM = 571), chronic kidney disease (ICD-9-CM = 585), diabetes (ICD-9-CM = 250), Chronic obstructive pulmonary disease (ICD9-CM $=491,492,496)$, autoimmune disease (ICD-9-CM = 710.0, 714.0, 720.0), cardiovascular disease (ICD-9-CM = 410-414), stroke (ICD-9-CM = 430-438), and gout (ICD-9-CM =274). These comorbidities were defined as a disease diagnosed at least twice in outpatient department or one admission within three years before the index date. In addition, the use of warfarin and statin were included in this study.

\section{Statistical analyses}

Chi-square and t-tests were used to compare the differences between discrete and continuous variables. Conditional logistic regression analysis was used to compare the effects of TCM usage on reducing the risk of dementia among patients with 
Parkinson's disease in different subgroups. The effects of TCM usage were analyzed to see if there were significant differences between the following subgroups: the duration of taking TCM ( $\geq 90$ days versus < 90 days), age (50-64 versus $\geq 65$ ), and gender. Adjustments were made for age, sex, hypertension, hyperlipidemia, chronic liver disease, chronic kidney disease, diabetes, COPD, autoimmune disease, cardiovascular disease, stroke, gout, TCM usage, warfarin usage, statin usage and follow-up periods. The statistical software used was SPSS version 18.0 (SPSS Inc., Chicago, IL, USA).

\section{Results}

The study design was a nested case-control study (Fig. 1). The study subjects were over 50 years old with newly diagnosed Parkinson's disease (ICD-9-CM =332) at least twice in outpatient department or one admission from year 2000 to 2010 ( $N=7990$ ). Patients diagnosed of dementia (ICD-9-CM = 290.0-290.4, 294.1, 331.0-331.2) before the diagnosis of Parkinson's disease were excluded ( $N=6211)$. The patients in the dementia group were newly diagnosed of dementia at least twice in outpatient department or one admission after diagnosis of Parkinson's disease and at least 3 years apart $(\mathrm{N}=1299)$. Non-dementia group were patients not diagnosed of dementia after the diagnosis of Parkinson's disease and were matched in a 1:1 ratio with respect to age ( \pm 2 years), gender and the diagnosed year of Parkinson's disease with patients in the dementia group $(N=981)$.

Demographic characteristics of dementia and non-dementia in cohort of Parkinson's disease were shown in Table 1. 
Table 1

Demographic characteristics of dementia and non-dementia in cohort of Parkinson's disease

\begin{tabular}{|c|c|c|c|c|c|}
\hline & \multicolumn{2}{|c|}{$\begin{array}{l}\text { Dementia } \\
(\mathrm{N}=981)\end{array}$} & \multicolumn{2}{|c|}{$\begin{array}{l}\text { Non-dementia } \\
(\mathrm{N}=981)\end{array}$} & \multirow[b]{2}{*}{$p$-value } \\
\hline & $\mathrm{n}$ & $\%$ & $\mathrm{n}$ & $\%$ & \\
\hline Age & & & & & 0.226 \\
\hline $50-64$ & 42 & 4.3 & 42 & 4.3 & \\
\hline $65-79$ & 515 & 52.5 & 552 & 56.3 & \\
\hline$\geq 80$ & 424 & 43.2 & 387 & 39.4 & \\
\hline Mean \pm SD & \multicolumn{2}{|c|}{$78.3 \pm 7.3$} & \multicolumn{2}{|c|}{$77.8 \pm 7.1$} & 0.097 \\
\hline Gender & & & & & 1 \\
\hline Female & 517 & 52.7 & 517 & 52.7 & \\
\hline Male & 464 & 47.3 & 464 & 47.3 & \\
\hline Hypertension & 714 & 72.8 & 682 & 69.5 & 0.111 \\
\hline Hyperlipidemia & 223 & 22.7 & 280 & 28.5 & 0.003 \\
\hline Chronic liver disease & 110 & 11.2 & 103 & 10.5 & 0.611 \\
\hline Chronic kidney disease & 90 & 9.2 & 49 & 5.0 & $<0.001$ \\
\hline Diabetes & 316 & 32.2 & 297 & 30.3 & 0.355 \\
\hline COPD & 260 & 26.5 & 169 & 17.2 & $<0.001$ \\
\hline Autoimmune disease & 22 & 2.2 & 16 & 1.6 & 0.326 \\
\hline Cardiovascular disease & 282 & 28.7 & 280 & 28.5 & 0.920 \\
\hline Stroke & 496 & 50.6 & 349 & 35.6 & $<0.001$ \\
\hline Gout & 104 & 10.6 & 112 & 11.4 & 0.564 \\
\hline $\begin{array}{l}\text { Medication usage } \\
\text { TCM }\end{array}$ & 295 & 30.1 & 377 & 38.4 & $<0.001$ \\
\hline Warfarin & 35 & 3.6 & 28 & 2.9 & 0.370 \\
\hline Statin & 209 & 21.3 & 289 & 29.5 & $<0.001$ \\
\hline Follow-up period (years) & $5.2 \pm$ & & $5.2 \pm$ & & 0.953 \\
\hline
\end{tabular}


In the univariate analysis, case and control patients were similar with regard to age, sex, hypertension, chronic liver disease, diabetes, autoimmune disease, cardiovascular disease, gout, warfarin usage and follow-up periods. A history of chronic kidney disease (CKD), chronic obstructive pulmonary disease (COPD), and stroke were more associated with dementia group. A history of TCM usage, statin usage and hyperlipidemia were more associated with non-dementia group (Table 1).

Certain kinds of diseases and medication usage were significantly associated with the risk of dementia in cohort of Parkinson's disease after the adjustment for confounding variables (Table 2). The association decreased significantly between dementia and the usage of TCM (adjusted odds ratio $=0.67, P<0.001$ ) and statin (adjusted odds ratio $=0.57, \mathrm{P}<0.001$ ). However, there was a markedly increasing association between dementia and CKD (adjusted odds ratio $=1.96, \mathrm{P}=0.001$ ), COPD (adjusted odds ratio $=1.76, \mathrm{P}<$ $0.001)$ and stroke (adjusted odds ratio $=1.90, \mathrm{P}<0.001)($ Table 2$)$. 
Table 2

Conditional logistic regression of risk of dementia

\begin{tabular}{|c|c|c|c|c|c|c|}
\hline & $\begin{array}{l}\text { Crude } \\
\text { OR }\end{array}$ & 95\% C.I. & $\begin{array}{l}\mathrm{p}- \\
\text { value }\end{array}$ & Adjusted $\mathrm{OR}^{\dagger}$ & 95\% C.I. & p-value \\
\hline TCM & 0.68 & $0.56-0.82$ & $\stackrel{<}{0.001}$ & 0.67 & $0.54-0.82$ & $<0.001$ \\
\hline Hypertension & 1.17 & $0.96-1.43$ & 0.111 & 1.05 & $0.84-1.3$ & 0.685 \\
\hline Hyperlipidemia & 0.72 & $0.58-0.89$ & 0.002 & 0.90 & $0.69-1.18$ & 0.454 \\
\hline Chronic liver disease & 1.07 & $0.81-1.41$ & 0.623 & 1.18 & $0.87-1.59$ & 0.289 \\
\hline Chronic kidney disease & 1.91 & $1.33-2.74$ & $<.001$ & 1.96 & $1.33-2.91$ & 0.001 \\
\hline Diabetes & 1.09 & $0.9-1.32$ & 0.360 & 1.08 & $0.87-1.34$ & 0.491 \\
\hline COPD & 1.86 & $1.47-2.35$ & 0.000 & 1.76 & $1.37-2.26$ & $<0.001$ \\
\hline Autoimmune disease & 1.37 & $0.72-2.62$ & 0.332 & 1.26 & $0.64-2.48$ & 0.506 \\
\hline $\begin{array}{l}\text { Cardiovascular } \\
\text { disease }\end{array}$ & 1.01 & $0.83-1.23$ & 0.918 & 1.02 & $0.81-1.27$ & 0.884 \\
\hline Stroke & 1.85 & $1.54-2.23$ & $<001$ & 1.90 & $1.56-2.32$ & $<0.001$ \\
\hline Gout & 0.92 & $0.69-1.22$ & 0.564 & 0.92 & $0.67-1.25$ & 0.581 \\
\hline Warfarin & 1.28 & $0.76-2.16$ & 0.355 & 1.20 & $0.68-2.1$ & 0.529 \\
\hline Statin & 0.63 & $0.51-0.78$ & $<.001$ & 0.57 & $0.43-0.75$ & $<0.001$ \\
\hline \multicolumn{7}{|c|}{ COPD: Chronic obstructive pulmonary disease. } \\
\hline \multicolumn{7}{|c|}{ TCM: Traditional Chinese medicine. } \\
\hline $\begin{array}{l}\text { †Adjusted for TCM, hyp } \\
\text { diabetes, COPD, autoim }\end{array}$ & $\begin{array}{l}\text { ension, } \\
\text { ne dise }\end{array}$ & $\begin{array}{l}\text { ipidemia, } \\
\text { ardiovascl }\end{array}$ & $\begin{array}{l}\text { onic li } \\
\text { disea }\end{array}$ & $\begin{array}{l}\text { lisease, chron } \\
\text { troke, gout, w }\end{array}$ & $\begin{array}{l}\text { idney disec } \\
\text { arin, and st }\end{array}$ & \\
\hline
\end{tabular}

The risk of dementia in cohort of Parkinson's disease was also associated with the duration of usage of Traditional Chinese Medicine (Table 3). The risk of dementia was significantly decreased with the usage of both TCM $<90$ days (adjusted odds ratio, $0.69 ; 95 \% \mathrm{Cl}, 0.54-0.86$ ) and $\geq 90$ days (adjusted odds ratio, $0.62 ; 95 \% \mathrm{Cl}, 0.44-0.88)$, especially in the group who used TCM for more than 90 days. 
Table 3

Conditional logistic regression of risk of dementia

\begin{tabular}{|c|c|c|c|c|c|c|c|c|}
\hline & $\mathbf{N}$ & $\begin{array}{l}\text { No. of } \\
\text { dementia }\end{array}$ & $\begin{array}{l}\text { Crude } \\
\text { OR }\end{array}$ & 95\% C.I. & $\begin{array}{l}\text { p- } \\
\text { value }\end{array}$ & $\begin{array}{l}\text { Adjusted } \\
\mathrm{OR}^{\dagger}\end{array}$ & 95\% C.I. & $\begin{array}{l}\mathrm{p}- \\
\text { value }\end{array}$ \\
\hline \multicolumn{9}{|c|}{ TCM (days) } \\
\hline None & 1290 & 686 & 1 & & & 1 & & \\
\hline$<90$ & 499 & 223 & 0.70 & $\begin{array}{l}0.56- \\
0.87\end{array}$ & 0.001 & 0.69 & $\begin{array}{l}0.54- \\
0.86\end{array}$ & 0.001 \\
\hline$\geq 90$ & 173 & 72 & 0.63 & $\begin{array}{l}0.46- \\
0.87\end{array}$ & 0.005 & 0.62 & $\begin{array}{l}0.44- \\
0.88\end{array}$ & 0.007 \\
\hline \multicolumn{9}{|c|}{ TCM: Traditional Chinese medicine. } \\
\hline
\end{tabular}

Though no statistically significant interaction was found among the risk of dementia in cohort of Parkinson's disease and the TCM usage for $<90$ days or $\geq 90$ days between the age of 50 to 64 years, protection tendency was revealed (adjusted odds ratio, 0.30 and 0.07 , respectively). Among the patients older than 65 years old, the risk of dementia was significantly decreased with the usage of TCM for < 90 days (adjusted odds ratio, $0.71 ; 95 \% \mathrm{Cl}, 0.56-0.9$ ) and $\geq 90$ days (adjusted odds ratio, $0.67 ; 95 \% \mathrm{Cl}$, 0.47-0.95) (Table 4). 
Table 4

Subgroup analysis of conditional logistic regression of risk of dementia

\begin{tabular}{|c|c|c|c|c|c|c|c|c|}
\hline & $\mathbf{N}$ & $\begin{array}{l}\text { No. of } \\
\text { dementia }\end{array}$ & $\begin{array}{l}\text { Crude } \\
\text { OR }\end{array}$ & 95\% C.I. & $\begin{array}{l}\mathrm{p}- \\
\text { value }\end{array}$ & $\begin{array}{l}\text { Adjusted } \\
\text { OR }\end{array}$ & 95\% C.I. & $\begin{array}{l}\mathrm{p} \text { - } \\
\text { value }\end{array}$ \\
\hline \multicolumn{9}{|c|}{$\begin{array}{l}\text { Age }=50- \\
64\end{array}$} \\
\hline \multicolumn{9}{|c|}{$\begin{array}{l}\text { TCM } \\
\text { (days) }^{\dagger}\end{array}$} \\
\hline None & 47 & 28 & 1 & & & 1 & & \\
\hline$<90$ & 26 & 11 & 0.45 & $\begin{array}{l}0.13- \\
1.53\end{array}$ & 0.199 & 0.30 & $\begin{array}{l}0.06- \\
1.56\end{array}$ & 0.152 \\
\hline$\geq 90$ & 11 & 3 & 0.11 & $\begin{array}{l}0.01- \\
0.97\end{array}$ & 0.047 & 0.07 & $\begin{array}{l}0.005- \\
1.03\end{array}$ & 0.052 \\
\hline \multicolumn{9}{|c|}{ Age $\geq 65$} \\
\hline \multicolumn{9}{|c|}{$\begin{array}{l}\text { TCM } \\
\text { (days) }^{\ddagger}\end{array}$} \\
\hline None & 1243 & 658 & 1 & & & 1 & & \\
\hline$<90$ & 473 & 212 & 0.72 & $\begin{array}{l}0.58- \\
0.90\end{array}$ & 0.004 & 0.71 & $\begin{array}{l}0.56- \\
0.90\end{array}$ & 0.004 \\
\hline$\geq 90$ & 162 & 69 & 0.68 & $\begin{array}{l}0.49- \\
0.94\end{array}$ & 0.020 & 0.67 & $\begin{array}{l}0.47- \\
0.95\end{array}$ & 0.025 \\
\hline \multicolumn{9}{|c|}{ Female } \\
\hline \multicolumn{9}{|c|}{$\begin{array}{l}\text { TCM } \\
\text { (days) }\end{array}$} \\
\hline None & 683 & 368 & 1 & & & 1 & & \\
\hline$<90$ & 269 & 117 & 0.63 & $\begin{array}{l}0.46- \\
0.85\end{array}$ & 0.003 & 0.64 & $0.46-0.9$ & 0.010 \\
\hline$\geq 90$ & 82 & 32 & 0.52 & $\begin{array}{l}0.32- \\
0.86\end{array}$ & 0.010 & 0.50 & $\begin{array}{l}0.29- \\
0.86\end{array}$ & 0.013 \\
\hline
\end{tabular}

TCM: Traditional Chinese medicine.

†: Adjusted for TCM, hypertension, hyperlipidemia, chronic liver disease, diabetes, stroke, gout and statin.

‡: Adjusted for TCM, hypertension, hyperlipidemia, chronic liver disease, chronic kidney disease, diabetes, COPD, autoimmune disease, cardiovascular disease, stroke, gout, warfarin, and statin. 


\begin{tabular}{|c|c|c|c|c|c|c|c|c|}
\hline & $\mathbf{N}$ & $\begin{array}{l}\text { No. of } \\
\text { dementia }\end{array}$ & $\begin{array}{l}\text { Crude } \\
\text { OR }\end{array}$ & 95\% C.I. & $\begin{array}{l}\text { p- } \\
\text { value }\end{array}$ & $\begin{array}{l}\text { Adjusted } \\
\text { OR }\end{array}$ & 95\% C.I. & $\begin{array}{l}\text { p- } \\
\text { value }\end{array}$ \\
\hline \multicolumn{9}{|c|}{$\begin{array}{l}\text { TCM } \\
\text { (days) }\end{array}$} \\
\hline None & 607 & 318 & 1 & & & 1 & & \\
\hline$<90$ & 230 & 106 & 0.78 & $\begin{array}{l}0.57- \\
1.06\end{array}$ & 0.110 & 0.71 & $\begin{array}{l}0.51- \\
0.99\end{array}$ & 0.042 \\
\hline$\geq 90$ & 91 & 40 & 0.73 & $\begin{array}{l}0.48- \\
1.12\end{array}$ & 0.156 & 0.70 & $\begin{array}{l}0.44- \\
1.10\end{array}$ & 0.124 \\
\hline \multicolumn{9}{|c|}{ TCM: Traditional Chinese medicine. } \\
\hline \multicolumn{9}{|c|}{$\begin{array}{l}\text { †: Adjusted for TCM, hypertension, hyperlipidemia, chronic liver disease, diabetes, stroke, gout and } \\
\text { statin. }\end{array}$} \\
\hline \multicolumn{9}{|c|}{$\begin{array}{l}\text { Ғ: Adjusted for TCM, hypertension, hyperlipidemia, chronic liver disease, chronic kidney disease, } \\
\text { diabetes, COPD, autoimmune disease, cardiovascular disease, stroke, gout, warfarin, and statin. }\end{array}$} \\
\hline
\end{tabular}

Among female patients, the risk of dementia was markedly decreased with the usage of TCM for $<90$ days (adjusted odds ratio, $0.64 ; 95 \% \mathrm{Cl}, 0.46-0.9$ ) and $\geq 90$ days (adjusted odds ratio, $0.50 ; 95 \% \mathrm{Cl}$, 0.29-0.86). Among male patients, TCM usage for less than 90 days was beneficial for reducing the risk of dementia (adjusted odds ratio, $0.71 ; 95 \% \mathrm{Cl}, 0.51-0.99$ ), but TCM usage for more than 90 days demonstrated no statistical significance; nonetheless, the protection tendency in this group was also revealed (adjusted odds ratio, 0.70). (Table 4)

\section{Discussion}

This study provided support for the benefits from the use of TCM in reducing the risk of dementia in cohort of Parkinson's disease. The risk of dementia in patients with Parkinson's disease decreased markedly by using TCM $<90$ days and $\geq 90$ days, especially in women who took TCM for more than 90 days, which indicates the use of TCM for longer time may present more benefits.

Overall, this study showed the protection tendency of TCM usage in preventing dementia for patients previously diagnosed with PD. Statistically significant association was found between the use of TCM and regression of dementia risk in the subgroups of age $\geq 65$ years, female patients using TCM for < 90 days and $\geq 90$ days and male patients using TCM for less than 90 days. Protection tendency under TCM treatment was revealed among all of the target population.

There are many common causes of dementia, and we categorized them into two types: First, neurodegenerative related, such as Alzheimer disease (AD), dementia with Lewy bodies, frontotemporal dementia, and Parkinson's disease dementia (PDD), which are nearly irreversible and ceasing the deterioration would be the treatment target. Second, non-neurodegenerative related, such as vascular dementia, which may be reversible. Aggressive treatment in golden period and slowing down the 
progression are the treatment goal for the latter group.[1-2] Parkinson's disease would lead to dementia itself, and it can also be accompanied with other causes of dementia.[8-9]

Decreased number of cholinergic neurons and decreased cortical acetylcholinesterase (AChE) activity in brain were significantly noted in PDD and AD patients, which suggest cholinesterase inhibitors can improve cognitive function in dementia.[10-12] Besides, there are many metabolic and cardiovascular risk factors that would lead to dementia. Thus, prevention of the above risk factors could prevent dementia development. Previous studies demonstrated that natural compounds, which act as antioxidative, have positive effects on neuroprotection.[13] Some TCM contain contributing factors as mentioned above on preventing dementia, such as AChE inhibitors and neuronal injury inhibitors. Part of the TCM also exhibit anti-inflammation, anti-hypertension, anti-hyperlipidemia, anti-diabetes, and anticonvulsion characteristics. $[7,14]$ Since the severity of PD is a risk factor of dementia development, meliorating or slowing down the progression of PD can prevent the development of dementia.[15] It was shown that Chinese herbal medicine act as antioxidant, anti-inflammatory, and anti-apoptosis agents.[16] Previous studies showed that Chinese herb formulas improve symptoms of PD, and reduce the use of dopaminergic drugs and prevent the occurrence of dyskinesia.[17] The evidence from the studies above suggests that Chinese herb medicine is a potential treatment for neuroprotection in Parkinson's disease. [18] Therefore, TCM could relieve the symptoms of PD and further decrease the risk of dementia in PD.

TCM is a very popular and historic treatment of PD, particularly in Asian countries.[19] Nowadays, it is increasingly used worldwide, even in the West.[20] An important advantage of TCM for patients with PD is good compliance for long-term use because of its few side effects.[21] According to this study and previous researches, using TCM as a synergy and adjunctive treatment is highly recommended.

\section{Limitation}

This study presents some limitations. Focusing on Taiwan National Health Insurance Research Database may limit the generalizability of this study; therefore, researches on different ethnic groups are necessary to strengthen such correlation between TCM and dementia in PD patients. There are a variety of regimen

in TCM. Further studies are required to specify the effective TCM regimen for reducing the risk of dementia in patients with Parkinson's disease. However, identifying the effective intergradient of TCM compounds is rather challenging and the comprehensive mechanisms for TCM in reducing the risk of dementia in PD are yet unknown.

\section{Conclusions}

The results of this study show that after the use of TCM for more than 90 days, there is a significant reduction of nearly $38 \%$ in the risk of dementia for patients with Parkinson's disease, and beneficial effects in female patients age $\geq 65$ years are more significant. This study analyzes the effect of TCM in different subgroups, such as the duration of medication, age and gender, which can provide evidence for 
future researches in designing relevant clinical trials and can serve as a reference for TCM prescription in patients with PD in the future.

\section{Abbreviations}

PD

Parkinson's disease

TCM

Traditional Chinese Medicine

AChE

Acetylcholinesterase

$\mathrm{NHI}$

National Health Insurance

CKD

Chronic kidney disease

COPD

Chronic obstructive pulmonary disease

AD

Alzheimer disease

PDD

Parkinson's disease dementia

OR

Odds ratio

Cl

Confidence interval

\section{Declarations}

\section{Acknowledgement}

All the researchers participated in this study.

\section{Funding}

The authors have not declared a specific grant for this research from any funding agency in the public, commercial or not-for-profit sectors.

\section{Available of data and materials}

Data are available upon reasonable request.

\section{Ethics approval}


This study was approved by Chung Shan Medical University Hospital.

\section{Consent for publication}

Not applicable.

\section{Competing interests}

None declared.

\section{Authors' information}

\section{Affiliations}

${ }^{1}$ Institute of Medicine, Chung Shan Medical University, Taichung, Taiwan; ${ }^{2}$ Department of Family Medicine, Chung Shan Medical University Hospital, Taichung, Taiwan; ${ }^{3}$ Department of Medical Research, Chung Shan Medical University Hospital, Taichung, Taiwan; ${ }^{4}$ Department of Neurology, Chung Shan Medical University Hospital, Taichung, Taiwan; ${ }^{5}$ Department of Palliative Medicine, Chung Shan Medical University Hospital, Taichung, Taiwan; ${ }^{6}$ Center of Integrated Dementia Care at Taichung, Taiwan;

${ }^{7}$ Department of Rheumatology \& Immunology, Chung Shan Medical University Hospital; ${ }^{8}$ Graduate Institute of Integrated Medicine, China Medical University, Taichung, Taiwan.

\section{Contributions}

Y-T.L., C-Y.L., H-H.C., Y-H.W., J.CC.W. conceived and designed this manuscript. Y-H.W. contributed to acquisition of data. Y-T.L., C-Y.L., Y-H.W. analyzed and interpreted the data of this study: Y-T.L., C-Y.L., YH.W. wrote the original draft.

Y-T.L., C-Y.L., H-H.C., Y-H.W., J.CC.W. reviewed and edited the manuscript.

All authors were contributed to drafting and/or revising the article, and all authors approved the final version to be published.

\section{References}

1. Jellinger KA, Korczyn AD. Are dementia with Lewy bodies and Parkinson's disease dementia the same disease? BMC Med. 2018;16(1):34.

2. Svenningsson P, Westman E, Ballard C, Aarsland D. Cognitive impairment in patients with Parkinson's disease: diagnosis, biomarkers, and treatment. The Lancet Neurol. 2012;11(8):697-707.

3. Gratwicke J, Jahanshahi M, Foltynie T. Parkinson's disease dementia: a neural networks perspective. Brain. 2015;138(6):1454-76.

4. Emre $M$, Aarsland $D$, Brown R, et al. Clinical diagnostic criteria for dementia associated with Parkinson's disease. Mov Disord. 2007;22(12):1689-707. 
5. Buter T, Van Den Hout A, Matthews F, Larsen J, Brayne C, Aarsland D. Dementia and survival in Parkinson disease: a 12-year population study. Neurology. 2008;70(13):1017-22.

6. Gratwicke J, Jahanshahi M, Foltynie T. Parkinson's disease dementia: a neural networks perspective. Brain. 2015;138(6):1454-76.

7. Li XJ, Zhang HY. Potential anti-dementia agents in traditional Chinese medicine. Nat Prod Commun. 2009;4(6):877-86.

8. Clarfield AM. The reversible dementias: do they reverse? Ann Intern Med. 1988;109(6):476-86.

9. Caselli RJ. Current issues in the diagnosis and management of dementia. Semin Neurol. 2003;23(3):231.

10. Bohnen NI, Kaufer DI, Hendrickson R, Ivanco LS, Lopresti BJ, Constantine GM, Mathis CA, Davis JG, Moore RY, DeKosky ST. Cognitive correlates of cortical cholinergic denervation in Parkinson's disease and parkinsonian dementia. J Neurol. 2006;253(2):242-7.

11. Perry E, Curtis M, Dick D, Candy J, Atack J, Bloxham C, Blessed G, Fairbairn A, Tomlinson B, Perry R. Cholinergic correlates of cognitive impairment in Parkinson's disease: comparisons with Alzheimer's disease. J Neurol Neurosurg Psychiatry. 1985;48(5):413-21.

12. Ehrt U, Broich K, Larsen JP, Ballard C, Aarsland D. Use of drugs with anticholinergic effect and impact on cognition in Parkinson's disease: a cohort study. J Neurol Neurosurg Psychiatry. 2010;81(2):1605 .

13. Lam V, Hackett M, Takechi R. Antioxidants and dementia risk: consideration through a cerebrovascular perspective. Nutrients. 2016;8(12):828.

14. Gale SA, Acar D, Daffner KR. Dementia Am J Med. 2018;131(10):1161-9.

15. Stern Y, Marder K, Tang MX, Mayeux R. Antecedent clinical features associated with dementia in Parkinson's disease. Neurology. 1993;43(9):1690-0.

16. Fu W, Zhuang W, Zhou S, Wang X. Plant-derived neuroprotective agents in Parkinson's disease. Am J Transl Res. 2015;7(7):1189.

17. Zeng BY. Effect and mechanism of Chinese herbal medicine on Parkinson's disease. Int Rev Neurobiol. 2017;135:57-76.

18. Chen LW, Wang YQ, Wei LC, Shi M, Chan YS. Chinese herbs and herbal extracts for neuroprotection of dopaminergic neurons and potential therapeutic treatment of Parkinson's disease. CNS Neurol Disord Drug Targets. 2007;6(4):273-81.

19. Kum WF, Durairajan SS, Bian ZX, et al. Treatment of idiopathic Parkinson's disease with traditional chinese herbal medicine: a randomized placebo-controlled pilot clinical study. Evid Based Complement Alternat Med. 2011;2011:724353.

20. Smet PA. Herbal remedies. N Engl J Med. 2002;347(25):2046-56.

21. Zhang G, Xiong N, Zhang Z, et al. Effectiveness of traditional Chinese medicine as an adjunct therapy for Parkinson's disease: a systematic review and meta-analysis. PLoS One. 2015;10(3):e0118498. 


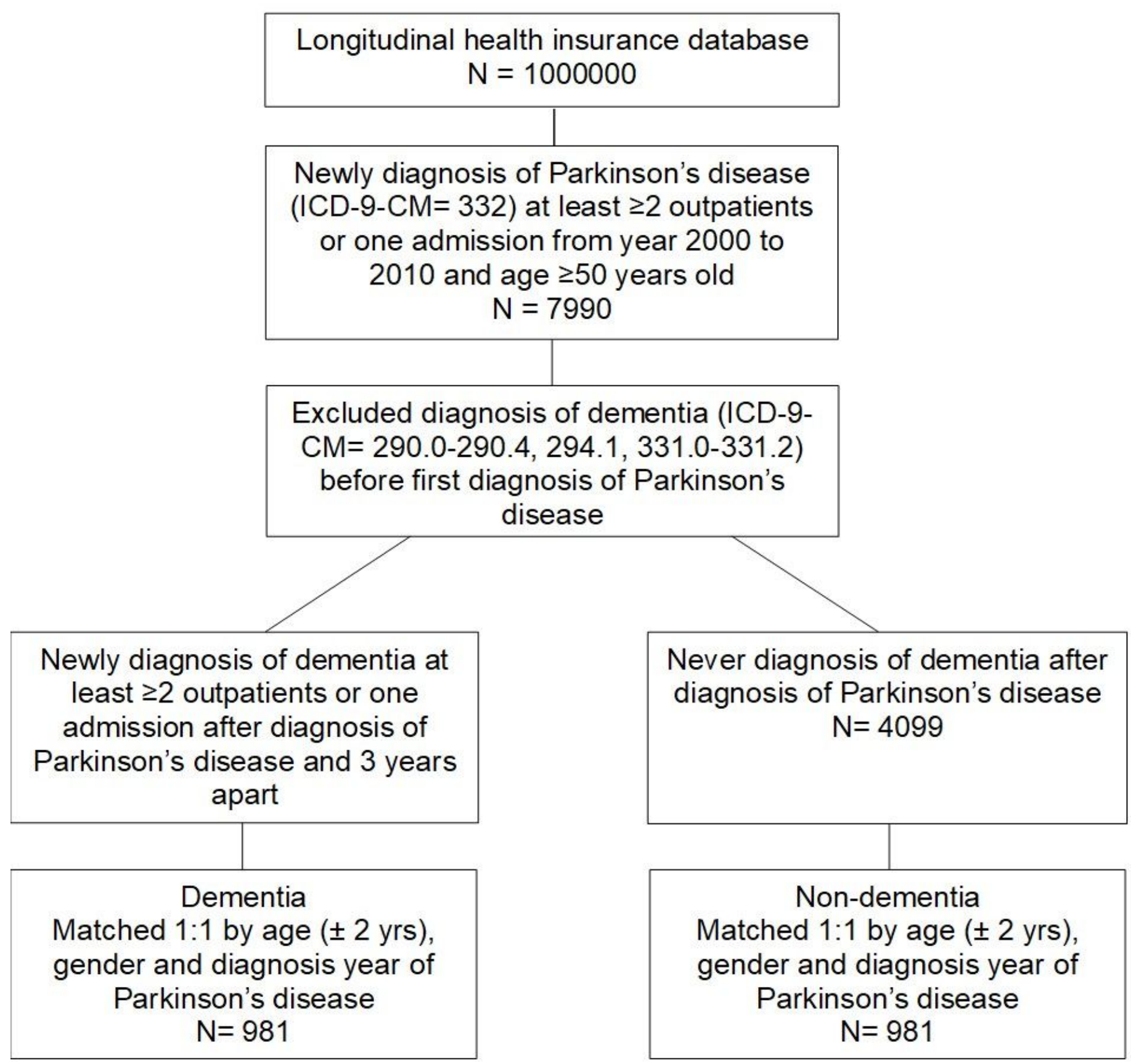

Figure 1

Flow diagram of nested case-control study of TCM and Dementia in 